\title{
Content Cytotoxicity Studies of Colorectal Carcinoma Cells Using Printed Impedance Sensors
}

\author{
Irmanisha Ibrahim ${ }^{1}$, Anis Nurashikin Nordin ${ }^{{ }^{2}}$, Ahmad Fairuzabadi Mohd Mansor ${ }^{3}$, Yumi \\ Zuhanis Has-Yun Hashim ${ }^{4}$, loana Voiculescu ${ }^{5}$ \\ ${ }^{1,4}$ Department of Biotechnology Engineering, Kulliyyah of Engineering, IIUM, Kuala Lumpur, Malaysia \\ ${ }^{2,3}$ Department of Electrical and Computer Engineering, Kulliyyah of Engineering, IIUM, \\ Kuala Lumpur, Malaysia \\ ${ }^{5}$ Department of Mechanical Engineering, School of Engineering, City College of New York, New York, USA \\ *Corresponding author, e-mail: anisnn@iium.edu.my
}

\begin{abstract}
Monitoring the effectiveness of drugs on cancer cells is crucial for chemotherapeutics studies. Invitro cell-based biosensors can be used as an alternative for characteristic studies of cells' response to drugs. Cell-based sensors provide real-time measurements and require smaller sample volumes compared to conventional T-flask measurement methods. This paper presents a biosensor that detects in real-time, impedance variations of human colon cancer, HCT-116 cells when treated with anti-cancer agent, 5-Fluorouracil (5-FU). Two different extracellular matrix (ECM); polyaniline and gelatin were tested and evaluated in terms of attachment quality. Polyaniline was found to provide the best attachment for HCT-116 cells and was used for cytotoxicity studies. Cytokinetic behavior indicated that 5-FU inhibited $\mathrm{HCT}-116$ cells at $I C_{50}$ of $6.8 \mu \mathrm{g} / \mathrm{mL}$. Trypan blue exclusion method for testing cell viability was used to validate the impedance measurements, where the cancer cell concentrations were reduced to $\sim 35 \%$ when treated with $2.5 \mu \mathrm{g} / \mathrm{mL}$, and $50 \%$ when treated with $6.8 \mu \mathrm{g} / \mathrm{mL}$. The results generated by the microfabricated impedance biosensor are comparable to the Trypan blue method since both gave similar cell growth trend. It can be concluded that the impedance biosensor has potential to be used as an alternative method in drug testing applications.
\end{abstract}

Keywords: cell-based biosensor, Impedance spectroscopy, ECIS, Cancer, HCT-116, anti-cancer drug

\section{Introduction}

Colorectal carcinoma is the third most common cancer in the world (1.4 million cases were detected in 2012), and represents the fourth leading cause of deaths due to cancer [1]. Mortality rates of colorectal cancer patients is highly dependent upon the disease's stage at diagnosis, with earlier stages having higher survival rates and lower risk of developing metastatic colorectal cancer. The first therapeutic approach for colorectal cancer is usually surgical resection. Better disease-free survival rates have been reported when surgery is followed by systemic chemotherapy [1-2]. In recent years, numerous efforts have been made to develop better chemotherapeutic procedures, resulting in improved outcomes and prolonged surviva [3]. Pre-clinical studies of cancerous cells especially understanding their interactions with drugs and toxics are of extreme importance [4].

Currently, conventional cytotoxicity assays such as 3-(4, 5-Dimethylthiazol-2-yl)-2, 5diphenyltetrazoliumbromide assay (MTT), Sulforhodamine B assay (SRB), and Adenosine triphosphate (ATP) [5] have been used to test the effect of drug or toxin on cells. These techniques require extensive preparation, large volumes of samples, stringent laboratory conditions, sophisticated instrumentation and high cost. Assays are an end-point detection method and are not able to provide continuous monitoring of a sample. In this case experiments using assays may not be suitable for personalized studies for drug testing.

To overcome these limitations, in recent years researchers have focused their efforts on the usage of cell-based impedance biosensor [4]. Conventional molecular biosensors are typically used to identify a specific agent by monitoring chemical, antibody, or nucleic acid changes [6]. The cell-based biosensors use whole cells as the bio-recognition element and can sense cell adhesion, spreading, growth, motility, and death by monitoring electrical current between the cell and electrode. Cell-based biosensors can be used to perform real-time 
dynamic analysis of the cell cycle [7], identification of environmental pollutant [8-9], and presence of bacteria and viruses [10]. Recently, cell-based biosensors have been successfully demonstrated to detect the cytotoxic effects of anti-cancer drugs on breast cancer-cells [11] and on lung cancer cells [12-13]. In cancer research, the study of cell adhesion to the extracellular matrix is of extreme importance since it's a precondition to tumour metastasis which is followed by formation of tumour due to unbounded cell proliferation [4]. Most anti-cancer agents target the cytoskeletons which are involved in the regulation of cell morphology and adhesion. Thus, through the usage of impedance cell-based biosensors, effectiveness of anti-cancer drugs can be evaluated by monitoring cellular adhesion and proliferation change induced by apoptosis.

In this study, colorectal cancer cells (HCT-116) are cultured on printed electrode coated with extracellular matrix (ECM) and the cancer cell's adhesion and proliferation are monitored via impedance biosensor. Two different ECM (gelatin and polyaniline) were used and compared in this work. Then, different concentration of the well-known anti-cancer drug 5-Fluorouracil (5FU) were used to prove that this biosensor is a viable method for chemosensitivity evaluation. The HCT-116 apoptosis was continuously monitored in real time using the impedance measurements generated by the biosensor.

\section{Experiments}

\subsection{Materials and Reagents}

The materials used in this research studies were as follows: Tissue culture flask, T-25 $\mathrm{cm}^{2}$ (Thermo Fisher Scientific, USA), $1 \%$ antibiotics $(100 \mathrm{U} / \mathrm{mL}$ penicillin, $0.1 \mathrm{~g} / \mathrm{L}$ streptomycin) or penstrep, Phosphate Buffer Saline pH 7.4 (PBS), 1\% acetic acid, 0.4\% Sulforhodamine B (SRB), and the anticancer drug, Fluorouracil or 5-FU (Sigma Aldrich, USA), Dulbecco's Modified Eagle Medium, Accutase, and Fetal Bovine serum (DMEM) (Gibco, USA), a printed circuit board (PCB), (Vanguard Electronic Sdn Bhd, Lab Tek II Chamber Slide), the cover (Thermo Fisher Scientific, USA), polyaniline (emeraldine base) (Sigma Aldrich, USA), the solvent for polyaniline N-Methyl-2-pyrrolidinone (NMP), ECM bovine gelatin (Gibco, UK), and silicon adhesive sealant (V-Tech, USA). All the chemicals that were used in this study were obtained commercially as reagent grade.

\subsection{Cell Culture}

Colon cancer cells (HCT-116) (CCL-247) were obtained from the American Type Culture Collection (ATCC, Manassas, VA). The cells are stored in $-150{ }^{\circ} \mathrm{C}$ freezer. To culture the cells they are revived and maintained in tissue culture flask $(T-25 \mathrm{~cm} 2)$ filled with DMEM containing $1 \%$ penicillin, $100 \mathrm{mg} / \mathrm{mL}$ streptomycin, and $10 \%(\mathrm{v} / \mathrm{v}) \mathrm{FBS}$, in an incubator at $37^{\circ} \mathrm{C} / 5 \% \mathrm{CO}_{2} / 90 \%$ humidity. The cell lines were sub-cultured.

For impedance measurements, the cells were cultured on each biosensor using the same DMEM's mixture and conditions as in T-flask. For seeding purposes, the flask containing HCT-116 cell lines were washed using phosphate buffer saline (PBS) to remove the apoptotic cells and spam media, and detached from the flask using Accutase. The cell suspensions were prepared by using standard tissue culture techniques.

\subsection{Design and Fabrication of ECIS Devices}

Each ECIS device consists of 8 biosensors complete with their culture chambers. Interdigitated electrodes were used for the design of the sensor as they showed best sensitivity to the growth of cells [14]. The sensors were printed on positive printed circuit board. Details on the fabrication steps for the ECIS device had been explained previously in [11]. A single sensor measures $360 \mu \mathrm{m} \times 500 \mu \mathrm{m}$, while the entire ECIS device with 8 sensors measures $80 \mathrm{~mm} \times 45$ $\mathrm{mm}$. An 8-well chamber slide was attached on top of the sensors using the silicon adhesive sealant which is non-toxic to the cells.

\subsection{Experimental Procedure}

Prior to cell seeding, the sensor board was sterilized by autoclaving at $120{ }^{\circ} \mathrm{C}$ for 20 minutes. Next, it was cleaned with $70 \%(\mathrm{v} / \mathrm{v})$ ethanol and irradiated under ultraviolet light for 2 hours. To promote cell attachment; the surface of the sensor is coated with ECM. Two different solutions namely $0.1 \%(\mathrm{w} / \mathrm{v})$ PANi and $0.1 \%(\mathrm{w} / \mathrm{v})$ gelatin were used as ECM and compared. The PANi solution was prepared by mixing the PANi-emeraldine base with N-methyl-2- 
pyrrolidinone (NMP) [15]. Meanwhile, the gelatin solution was prepared by mixing the gelatin powder with deionized water. The polyaniline and gelatin films were prepared by coating them directly on the electrode surface of the impedance biosensor. About 2 to $3 \mu \mathrm{l}$ of polyaniline and gelatin solutions were coated on separate sensors. Next, the sensors were either incubated at $37^{\circ} \mathrm{C} / 5 \% \mathrm{CO}_{2} / 90 \%$ humidity for 1 hour or placed in the biosafety cabinet at room temperature for 2 hours. Cell suspensions of HCT-116 cells $(1 \times 105$ cells $/ \mathrm{ml})$ were added to each well. Measurements were taken at 8 hour intervals for 120 hours. For the validation of the impedance measurements the results were compared with the Trypan blue dye exclusion method.

\subsection{Trypan Blue Dye Exclusion Method}

The Trypan blue dye exclusion method was described by [16]. In order to count the number of cells, the adherent cells were brought into suspension using Accutase. The cell suspension was mixed thoroughly by pipetting gently to disperse any clumps. Then, 10 to $20 \mu \mathrm{L}$ of the cell suspension were taken and added to similar volume of Trypan blue (dilution factor $=2$ ) by gently pipetting it. The Haemocytometer was cleaned and the cover-slip was moistened with water. The cover-slip was slide over the chamber back and forth using slight pressure until Newton's refraction rings appear (Newton's refraction rings are seen as rainbow-like rings under the cover-slip). Both sides of the chamber (approx. 5 to $10 \mu \mathrm{L}$ ) were filled with cell suspension and viewed under an inverted microscope using x20 magnification. The number of viable cells (seen as bright cells) and non-viable cells (stained blue) were counted and recorded. The concentration of viable and non-viable cells and the percentage of viable cells were calculated using the equation (1) below:

$$
C=\frac{n}{v}
$$

where $\mathrm{c}$ is the cell concentration $/ \mathrm{ml}$; $\mathrm{n}$ is the number of cells counted and $\mathrm{v}$ is the volume of sample counted.

\subsection{Impedance measurement}

The device containing 8 biosensors was connected to the Impedance Analyzer 4294A (Agilent, USA) as shown in Figure 1.

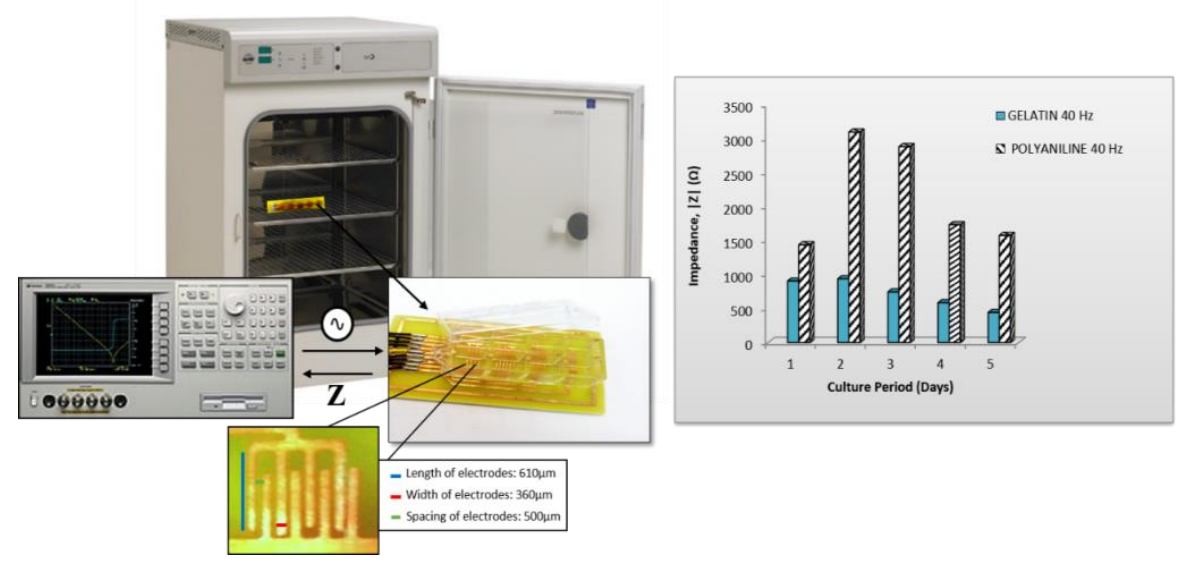

Figure 1. Setup for the impedance spectroscopy biosensor connected to the impedance analyzer

The frequency responses of cytotoxic effects were studied by monitoring in real time the impedance values of HCT-116 cells treated with different doses of 5-Fluorouracil and within frequency range from $40 \mathrm{~Hz}$ to $10 \mathrm{MHz}$ with 500 points in a logarithmic scale after 8 hour of drug treatment. In the frequency response experiment, HCT-116 cells without 5-Fluorouracil 
drug treatment were taken as positive control. The impedance values of the control untreated cells were compared to the impedance data of drug treated samples after 8 hour. All the measurements were repeated for three times and then averaged to obtain each impedance value for each frequency. The device contains 8 independent biosensors and each impedance biosensor is formed by interdigitated electrodes. The sensitivity of the biosensor was calculated by using equation (2) as follows:

$$
\text { Sensitivity }(f)=\left(\left|Z_{\text {cell drug }}(f)\right|-\left|Z_{\text {cell no drug }}(f)\right|\right) Q_{\text {cell }}{ }^{-1}
$$

where $f$ is the sensing frequency and $Q_{\text {cell }}$ is the maximum cell density (about $10^{5}$ cells $/ \mathrm{ml}$ ) [13] [9].

\subsection{5-Fluorouracil (5-FU)}

5-Fluorouracil was used to validate the applicability of this fabricated cell-based impedance biosensor in pharmacological bioassay. 5-FU drug was diluted with $100 \%$ DMSO to $1000 \mu \mathrm{g} / \mathrm{ml}$. Then, the dissolved compound was diluted with $10 \mu \mathrm{g} / \mathrm{ml}$ with deionize water. $\mathrm{In}$ order to determine the half-inhibitory concentration, $\mathrm{IC}_{50}$, twofold serial dilution was done in the range of 0.01 to $10 \mu \mathrm{g} / \mathrm{ml}$ in deionized water. This serial dilution gave eleven different 5 -FU concentrations $(0.1-10 \mu \mathrm{g} / \mathrm{ml})$ used for cancer cell testing. Compound solutions were mixed thoroughly by pipetting several times after each transfer. The drug solutions were kept at $4{ }^{\circ} \mathrm{C}$ in vials wrapped with aluminum foil to protect them from light.

\subsection{Determination of $\mathrm{IC}_{50}$}

The Sulforhodamine B (SRB) assay was conducted in order to get the half maximal inhibitory concentrations (IC50) of 5-FU [18-19]. The IC50 obtained was used in both conventional (Trypan blue dye exclusion method) and impedance tests for comparisons.

\subsection{Cytokinetic Studies Using Trypan Blue Dye Exclusion Method}

The conventional method of drug testing requires four sets of T-flask tests. Each set of tests used fifteen $25 \mathrm{~cm}^{2}$ T-flasks. The first test is the positive control, containing only cells. Second and third tests contained the low and the IC50 concentrations respectively. The flask containing cells were maintained in $37{ }^{\circ} \mathrm{C} / 5 \% \mathrm{CO}_{2} / 90 \%$ humidity incubator. All the tests were measured in triplicates. The cells were counted at 8-hourly interval for 120 hours. One flask from each set was taken, and cells were harvested and counted using Trypan blue dye exclusion method. Growth kinetic behavior of the cells was analyzed and expressed as changes in the average viable cells concentration versus time.

\subsection{Cytokinetic Studies Using Impedance Spectroscopy Biosensor}

Similarly, three sets of cultureware were prepared which are (i) control, (ii) low dose concentration of $5-\mathrm{FU}$, and (iii) treatment with IC50 concentration of 5-FU, respectively. Approximately $1 \times 105$ cells $/ \mathrm{mL}$ was seeded into each of the biosensor cultureware prior to incubation at $37^{\circ} \mathrm{C} / 5 \%, \mathrm{CO}_{2} / 90 \%$ humidity incubator. The drug concentrations from the SRB assay was added into treatment sets by following co-treatment mode (i.e. culturing cells simultaneously with drug). The impedance reading was taken at 8 hour intervals for 120 hours. The measurements were made in triplicates.

\subsection{Statistical Analysis}

Results are presented as mean \pm standard deviation. ECIS experiments were performed in duplicates and repeated for three times. Changes in the behavior of the cells (i.e., resistance) were recorded every 8 hour for 120 hours. Two-way analysis of variance and unpaired two-tailed Student's t-test were performed using JMP 8.0 (SAS Institute) and SigmaPlot 10.0 (Systat Software Inc.). Results were considered significant for ${ }^{*} p<0.05$ [14].

\section{Results and Discussion}

\subsection{Cellular Adhesion on Electrodes with Different ECM}

In cancer research, cell adhesion into extracellular matrix is the precondition to tumor metastasis [4]. Extracellular matrix (attachment factor) molecules share the ability to interact 
directly with cell membranes, making the matrix, as a whole, adhesive for cells [17]. Different ECM produces different scaffold-linked quality of adhesion of cells to the substrate to evaluate the effect of different extracellular matrix (gelatin and polyaniline) on the adhesion of colorectal cancer cells. From Figure 2, polyaniline had showed better colon cancer cell attachment on the electrode surface as compared to gelatin. This is based on the higher impedance measurement obtained, compared to the result of the gelatin.

Meanwhile, the optimum frequency obtained from untreated cells impedance measurement showed $40 \mathrm{~Hz}$ as the most sensitive frequency to detect the behavioral changes of the cancer cells. From both figure, cell attachment for the gelatin occurred at lower impedance value of about $1500 \Omega$ compared to polyaniline which generated higher impedance values of approximately $4500 \Omega$.

(i)
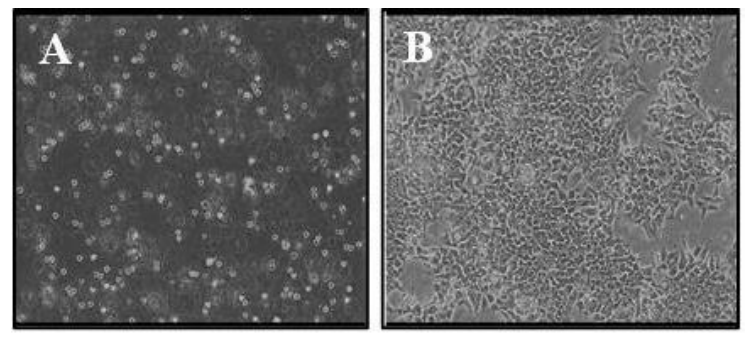

(a)

(ii)

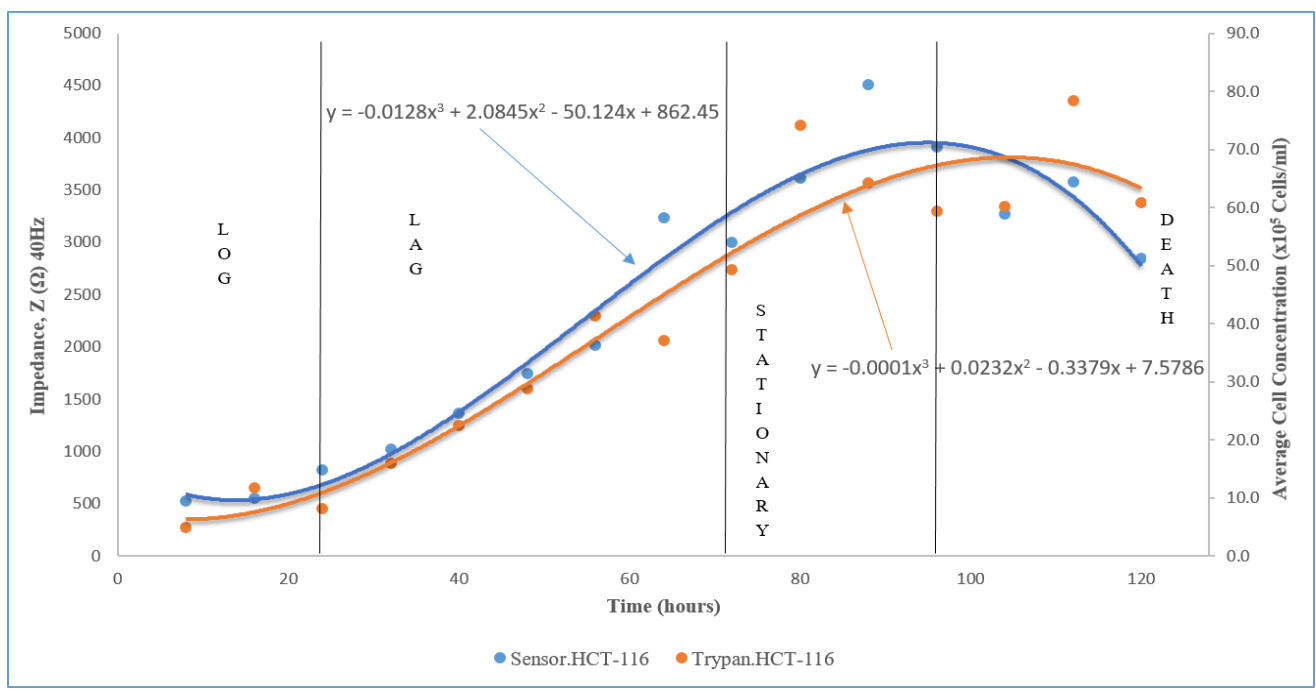

(b)

Figure 2. (i) The HCT-116 cells line in (a) cell suspension and (b) at $70 \%$ (ii) cell confluence.

Cell Growth profiles of HCT-116 cells generated from data obtained through Impedance Biosensor and Trypan Blue Exclusion method

Table 1. Student's t-test Results to Show the high Significance of Polyaniline as the Coating Material

\begin{tabular}{ccc}
\multicolumn{3}{c}{ Material } \\
\hline & Polyaniline & Gelatin \\
\hline$Z_{\text {mean }}$ & 2145.037333 & 742.95500 \\
Standard Deviation, $\sigma$ & 1047.230681 & 298.67406 \\
Degree of Freedom & 27 \\
$t$ & 4.8245 \\
$P(<0.05)$ & 0.000055538
\end{tabular}

**Student t-test descriptions: Student's t-test deals with the problems associated with inference based on "small" samples: the calculated mean (Xavg) and standard deviation $(\sigma)$ may by chance deviate from the "real" mean and standard deviation (i.e., what you'd measure if you had many more data items: a "large" sample). (Student's t-Test, n.d) 


\subsection{Kinetic Behaviors of the Cells-comparison of ECIS Method with Conventional Methods}

To prove that the impedance biosensor method can be used as an alternative to conventional methods, Figure 3 was plotted. Conventional growth profile tests using Trypan blue dye exclusion method was compared with measurements obtained by the biosensor. From Figure 3, it can be seen that the growth profiles obtained from conventional methods are similar to the impedance signatures generated by the impedance biosensor.

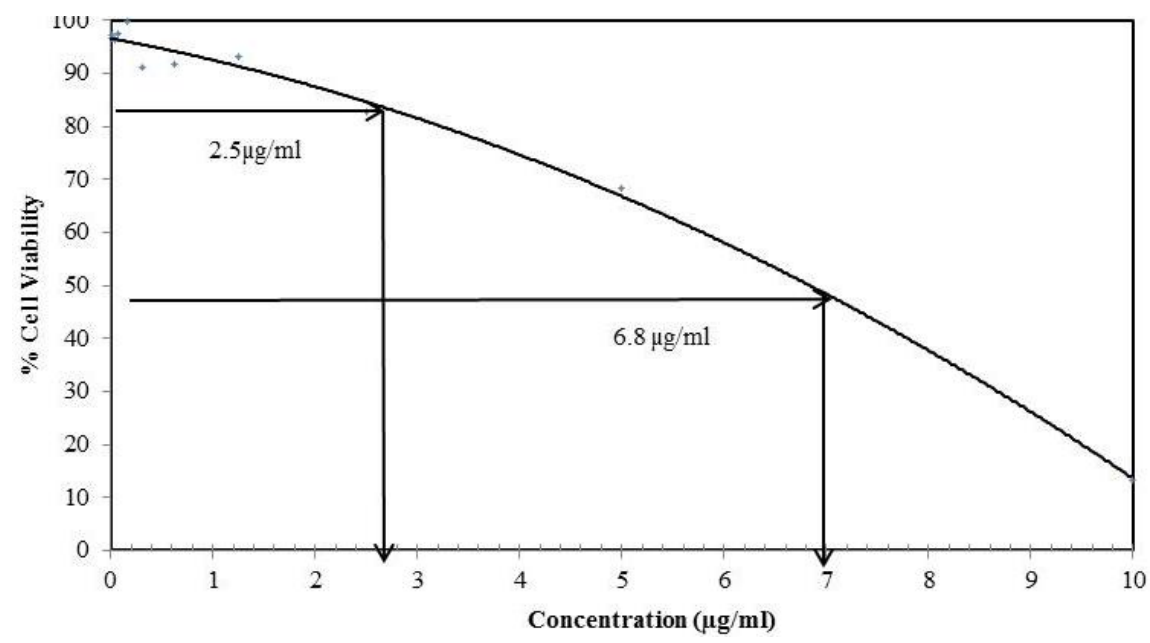

Figure 3. Growth profiles obtained from conventional methods are similar to the impedance signatures generated by the impedance biosensor

(i)
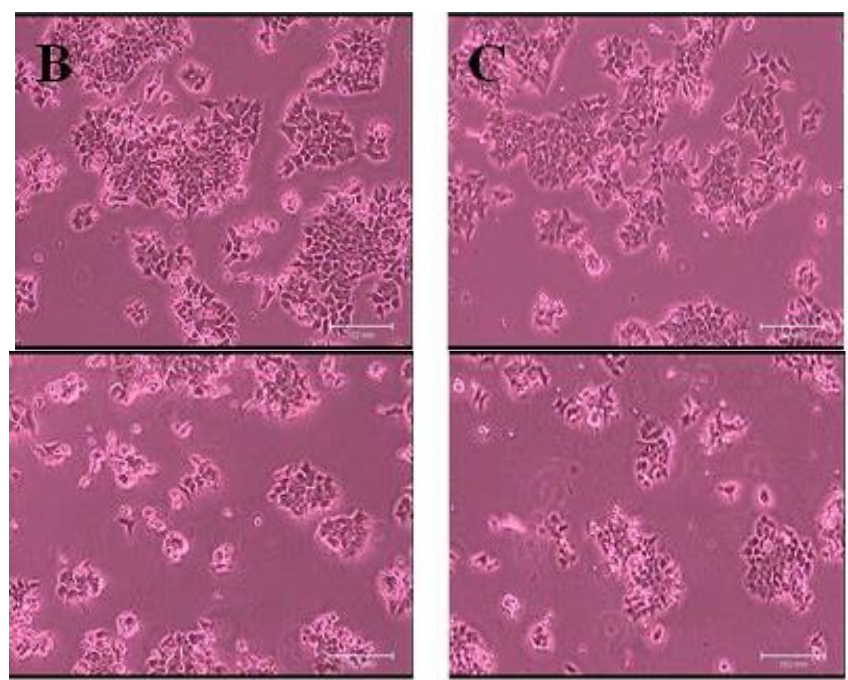

Figure 4. Percentage cell viability curves, (i) HCT-116 towards 5-FU concentrations. The drug was able to inhibit $50 \%$ of the cell growth at $5-\mathrm{FU}$ concentration $6.8 \mu \mathrm{g} / \mathrm{mL}$. Figure (ii) shows the attachment of cells on the flasks at 88 hour tested using the obtained IC50 concentration together with the controls and the low 5-FU concentration. (A) DMEM+Cells, (B) DMEM+Cells+DMSO, (C) DMEM+Cells+2.5 5-FU, (D) DMEM+Cells+6.8 5-FU.

Meanwhile, the results for both cytotoxicity tests are depicted in Figure 5 and 6 . The cytokinetic study of HCT-116 cells plots the cell concentrations versus time for (i) control (ii) low dosage $(2.5 \mu \mathrm{g} / \mathrm{ml})$ of $5-\mathrm{FU}$, and (iii) treatment with IC50 concentration of $5-\mathrm{FU}(6.8 \mu \mathrm{g} / \mathrm{ml})$. 


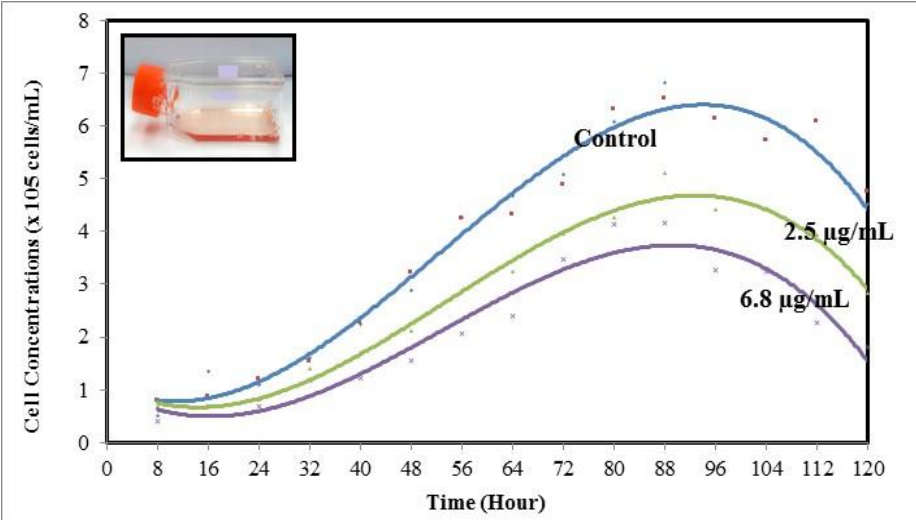

Figure 5. Cytokinetic study of HCT-116 cells using conventional method (Trypan Blue Exclusion Method) with low concentration $(2.5 \mu \mathrm{g} / \mathrm{mL})$ and half minimal concentration $(6.8 \mu \mathrm{g} / \mathrm{mL})$ of 5 -FU

From Figure 6(b), it can be seen that the impedance biosensors measurements follow the typical growth trend and kinetic behavior of mammalian cell culture curves as recorded in the Trypan blue method. In both cases, the number of viable cells decrease as the drug dosage increases.

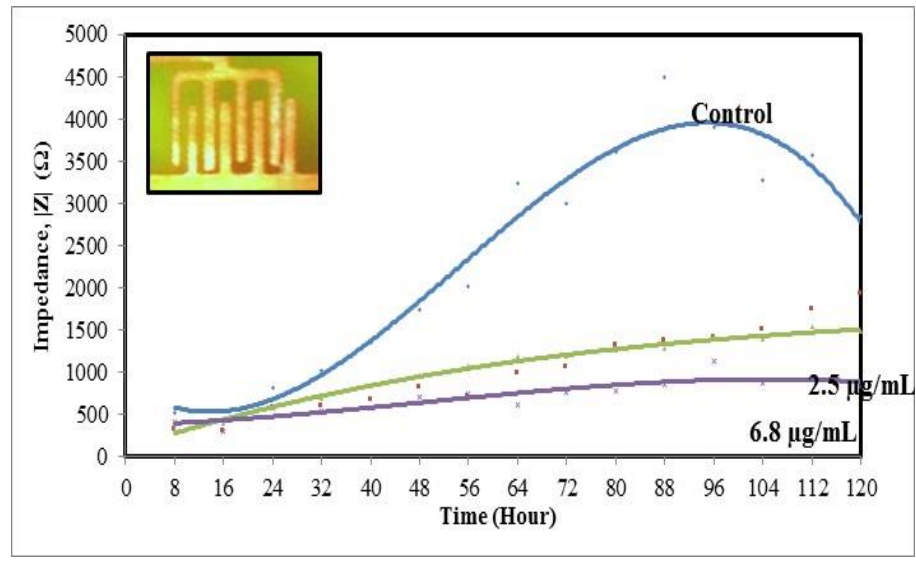

Figure 6. Cytokinetic study of HCT-116 cells using Impedance Biosensor at $40 \mathrm{~Hz}$ frequency with low concentration $(2.5 \mu \mathrm{g} / \mathrm{mL})$ and half minimal concentration $(6.8 \mu \mathrm{g} / \mathrm{mL})$ of $5-\mathrm{FU}$

Figure 6(b) shows the impedance biosensor results when the colorectal cancer cells are exposed to different concentrations of 5-FU. The result shows similar trends and comparable to the conventional method results as shown in Figure 5. To further evaluate the sensitivity of both methods (Trypan blue exclusion method and impedance biosensor devices (at $40 \mathrm{~Hz}$ ), the time dependent sensitivities are calculated using Equation (2) for 5-FU concentration of $2.5 \mu \mathrm{g} / \mathrm{mL}$ and $6.8 \mu \mathrm{g} / \mathrm{mL}$, and the plotted results are shown below in Figure 7 and 8. 


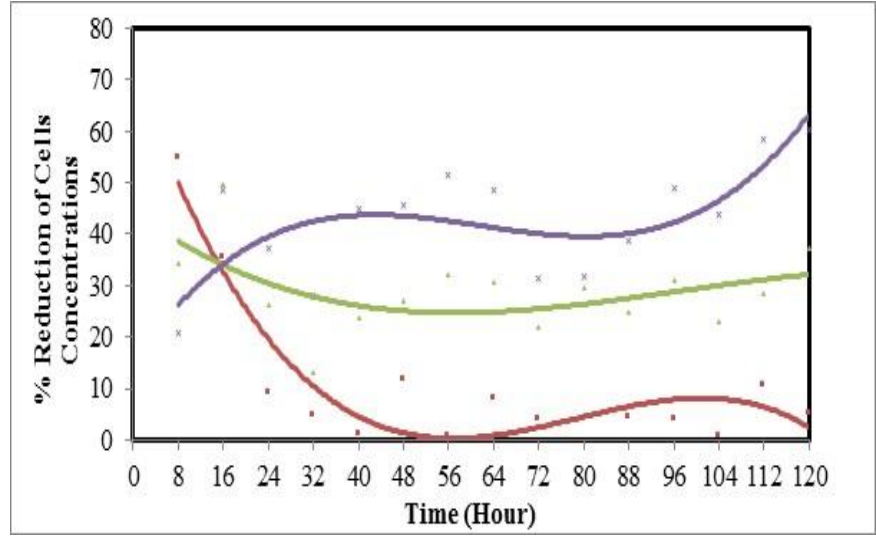

(a)

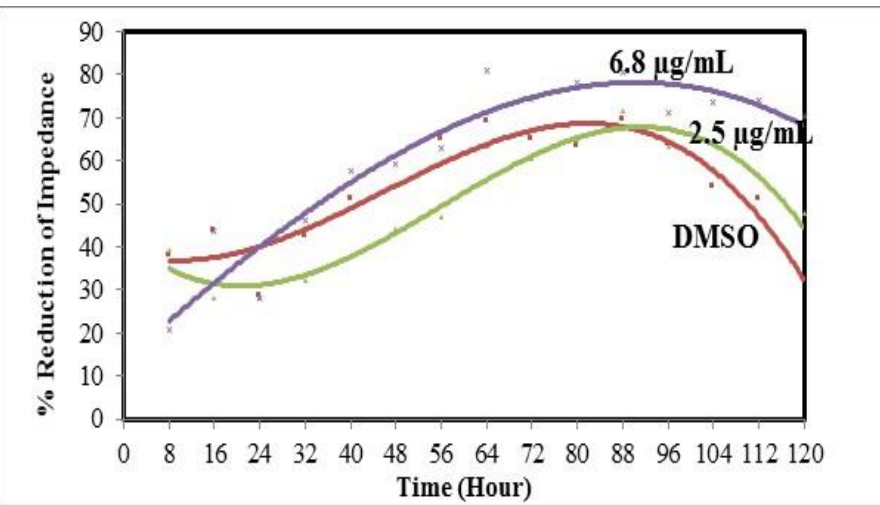

(b)

Figure 7. (a), (b) Sensitivity of Trypan blue exclusion method versus time

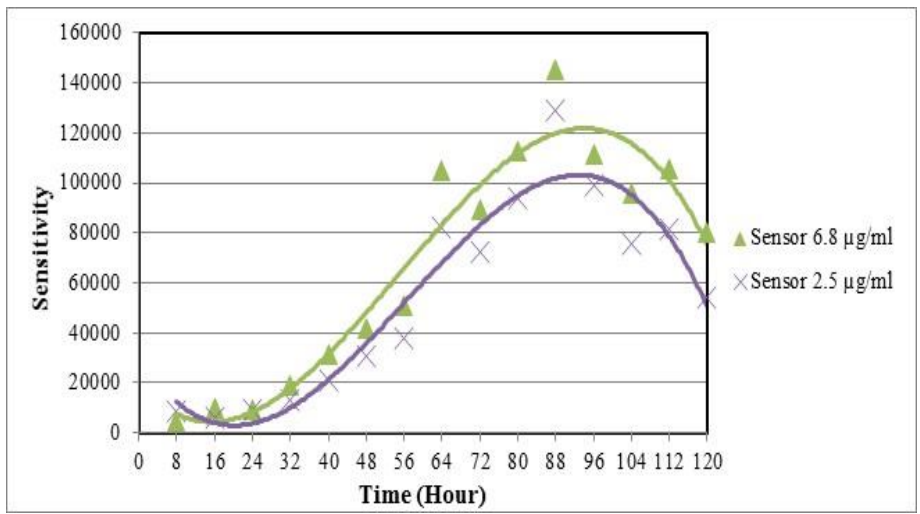

Figure 8. Sensitivity of ECIS biosensor versus time

As shown in Figure 7, the Trypan blue exclusion method has optimum sensitivity at hour 104 for flasks that have been treated with $2.5 \mu \mathrm{g} / \mathrm{mL}$ and $6.8 \mu \mathrm{g} / \mathrm{mL} 5-\mathrm{FU}$. The ECIS biosensor achieves optimum sensitivity earlier at hour 88 as shown in Figure 8 . The miniature size of the ECIS biosensor provides advantages in terms of lower sample volume requirements, being label-free and having faster response time compared to the conventional flask method. The comparison of sample volumes, cell-monitoring methods and label requirements between the ECIS biosensor and the conventional Trypan blue method is summarized in Table 2 - 
Supplementary Material. The conventional method requires fifteen flasks for each sample since each flask represents an end-point at hourly intervals to measure the cell concentrations. In comparison, the impedance biosensor only needs one well for each sample because the impedance is measured continuously by using impedance analyzer in real-time. Thus, there is no need for cell harvesting and counting of every sample of cells at each interval. Meanwhile, each well of the impedance biosensor only needs to be filled with approximately $0.5 \mathrm{~mL}$ of media compared to $5 \mathrm{~mL}$ in conventional method. The total cell concentrations used in impedance biosensor also is less than the cell concentration used for conventional method. These aspects reduced the cost of the experiment.

Table 2 Conventional Methods versus Biosensor

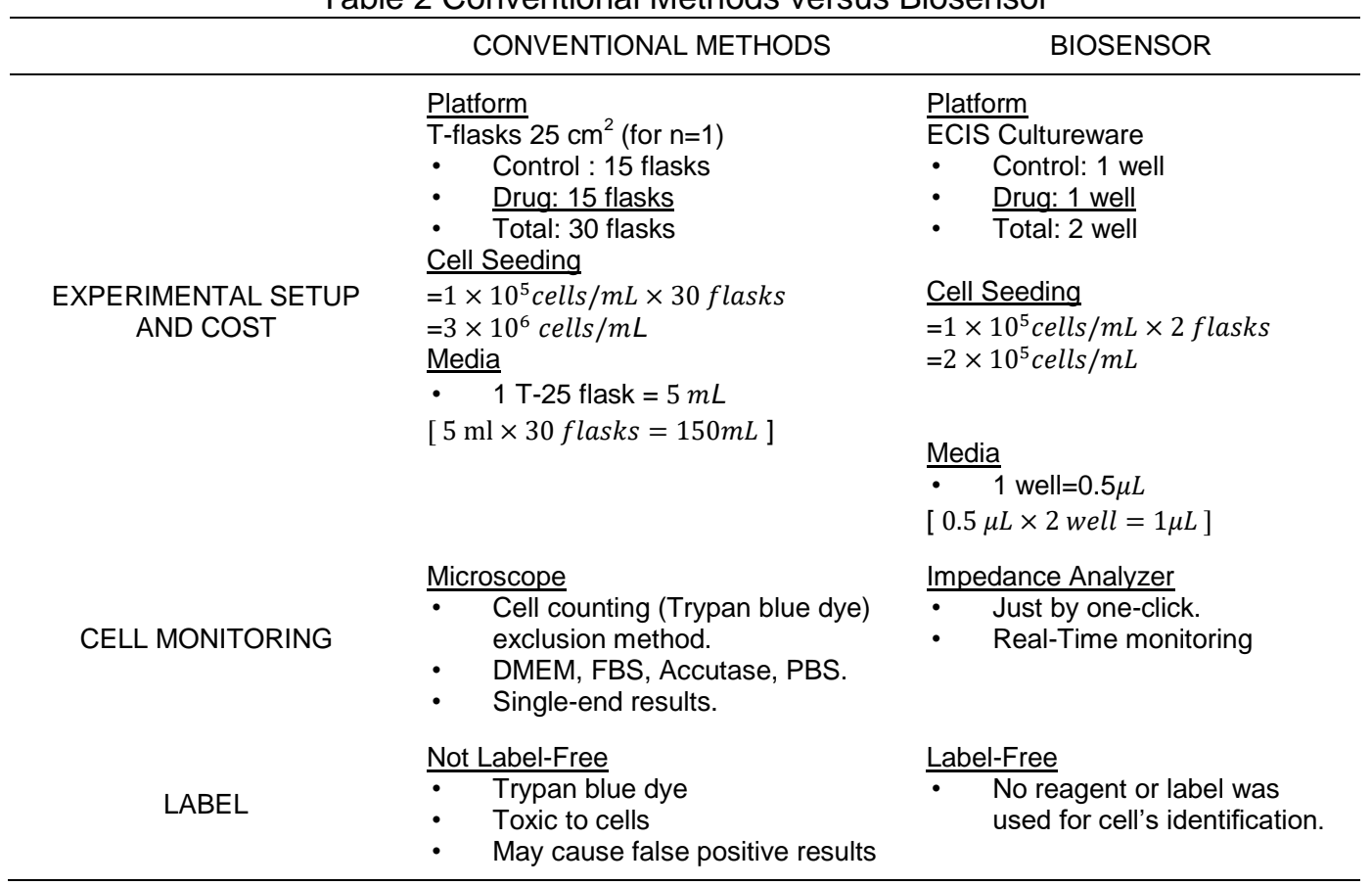

Cell monitoring and impedance measurements are straightforward when the impedance biosensor is used as compared to the conventional method. For impedance biosensor only the impedance analyzer was used in order to monitor the cells' impedance and there is no need to use a microscope. In the conventional Trypan blue exclusion method the microscope was intensively used to monitor and count the cell concentrations. In order to count the cells, the conventional biological methods need to use reagents such as phosphate buffer saline (PBS) to wash the flask, Accutase to detach the cells from the flasks, Dulbecco's modified eagle medium (DMEM) as the media for cell suspensions, and the Trypan blue dye to count the cell number under microscope. All these reagents increase the cost of experiment for the conventional biological methods.

The use of dye to label the cells is also not advisable because the dye is toxic to the cells when it is used for a long period of time. It can inhibit cell growth and kill the cells. The conventional method also has limitations because it gave single-end results compared to continuous cells monitoring by the impedance biosensor. The conventional biological methods to monitor the cell viability measure the cell concentrations manually by personnel, so, the chances to get false positive results were much higher in comparison with the results generated by the impedance biosensor.

\section{Conclusion}

This paper presents an impedance biosensor that uses polyaniline as ECM and $40 \mathrm{~Hz}$ as the optimum frequency to monitor the viability of colon cancer cells (HCT-116) when exposed 
to chemotherapeutical drugs. The cytokinetic behaviour of HCT-116 cells was established. Comparisons between Trypan blue dye exclusion method and biosensor impedance signature showed that they were comparable to each other. The impedance biosensor has been shown to be efficient to be used in drug testing applications since it can detect the changes in cell behaviour similar to the conventional flask-based assay. This paper concludes that the impedance biosensor can be used as an alternative method to the conventional methods used in drug testing applications. The impedance biosensor was demonstrated to provide advantages in the experimental works in terms of sensitivity, cost, time, and results.

\section{Acknowledgement}

This work is supported by the Malaysian Ministry of Science and Technology (MOSTI) E-Science Research Grant (SF12-019-0048) and also by the Malaysian Ministry of Education Prototype Research Grant Scheme (PRGS 12-010-0010).

\section{References}

[1] FA Haggar, RP Boushey. Colorectal Cancer Epidemiology: Incidence, Mortality, Survival, and Risk Factors. Clin. Colon Rectal Surg. Nov. 2009; 22(4): 191-197.

[2] J Franko et al., Treatment of Colorectal Peritoneal Carcinomatosis with Systemic Chemotherapy: a Pooled Analysis of North Central Cancer Treatment Group Phase III Trials N9741 and N9841. J. Clin. Oncol. Off. J. Am. Soc. Clin. Oncol. Jan. 2012; 30(3): 263-267.

[3] E Van Cutsem et al. Cetuximab Plus Irinotecan, Fluorouracil, and Leucovorin as First-line Treatment for Metastatic Colorectal Cancer: Updated Analysis of Overall Survival According to Tumor KRAS and BRAF Mutation Status. J. Clin. Oncol. Off. J. Am. Soc. Clin. Oncol. May 2011; 29(15): 20112019 ,.

[4] Q Liu et al. Impedance Studies of Bio-behavior and Chemosensitivity of Cancer Cells by MicroElectrode Arrays. Biosens. Bioelectron. Jan. 2009; 24(5): 1305-1310.

[5] L Ceriotti et al. Real-time Assessment of Cytotoxicity by Impedance Measurement on a 96-well Plate. Sens. Actuators B Chem. May 2007; 123(2): 769-778.

[6] F Asphahani, M Zhang. Cellular Impedance Biosensors for Drug Screening and Toxin Detection. Analyst. Aug. 2007; 132(9): 835-841.

[7] L Wang et al. Real-time, Label-free Monitoring of the Cell Cycle with a Cellular Impedance Sensing Chip. Biosens. Bioelectron. Jan. 2010; 25(5): 990-995.

[8] JJ Pancrazio, JP Whelan, DA Borkholder, W Ma, DA Stenger.Development and Application of CellBased Biosensors. Ann. Biomed. Eng. Nov. 1999; 27(6): 697-711.

[9] P Banerjee, S Kintzios, B Prabhakarpandian. Biotoxin Detection Using Cell-Based Sensors. Toxins. Nov. 2013; 5(12): 2366-2383.

[10] A Ahmed, JV Rushworth, NA Hirst, PA. Millner.Biosensors for Whole-cell Bacterial Detection. Clin. Microbiol. Rev. Jul. 2014; 27(3): 631-646.

[11] R Pradhan, S Rajput, M Mandal, A Mitra, S Das. Frequency Dependent Impedimetric Cytotoxic Evaluation of Anticancer Drug on Breast Cancer Cell. Biosens. Bioelectron. May 2014; 55: 44-50.

[12] R Eldawud et al. Real-time Analysis of the Effects of Toxic, Therapeutic and Sub-therapeutic Concentrations of Digitoxin on Lung Cancer Cells. Biosens. Bioelectron. Sep. 2014; 59: 192-199.

[13] BG Irianto, MR Mak'ruf, D Titisari. Identification of Lung Cancer Using a Back Propagation Neural Network. Indonesian Journal of Electrical Engineering and Computer Science. October 2015. 16(1): 91-97

[14] X Wang, X Xu, I. Acea Biosciences, Impedance Based Devices and Methods for Use in Assays. 2003.

[15] PR Bidez, S Li, AG Macdiarmid, EC Venancio, Y Wei, PI. Lelkes. Polyaniline, an Electroactive Polymer, Supports Adhesion and Proliferation Of Cardiac Myoblasts. J. Biomater. Sci. Polym. Ed. 2006; 17(1-2): 199-212.

[16] RI Freshney, RI Freshney. Culture of Specific Cell Types. in Culture of Animal Cells, John Wiley \& Sons, Inc., 2005.

[17] E Ruoslahti, MD Pierschbacher. New Perspectives in Cell Adhesion: RGD and Integrins. Science. Oct. 1987; 238(4826): 491-497.

[18] PM De Angelis, DH Svendsrud, KL Kravik, T Stokke. Cellular Response to 5-fluorouracil (5-FU) in 5FU-resistant Colon Cancer Cell Lines During Treatment and Recovery. Mol. Cancer. May 2006; 5: 20.

[19] S Flis, J Spławiński. Inhibitory Effects of 5-Fluorouracil and Oxaliplatin on Human Colorectal Cancer Cell Survival Are Synergistically Enhanced by Sulindac Sulfide. Anticancer Res. Jan. 2009; 29(1): $435-441$. 